\title{
Interplay between myeloid-derived suppressor cells (MDSCs) and Th17 cells: foe or friend?
}

\author{
Liang Wen ${ }^{1, *}$, Ping Gong ${ }^{2, *}$, Chao Liang ${ }^{1}$, Dawei Shou ${ }^{1}$, Baoqing Liu ${ }^{1}$, Yiwen Chen ${ }^{1}$, \\ Changqian Bao ${ }^{1}$, Li Chen ${ }^{1}$, Xiaowei Liu ${ }^{3}$, Tingbo Liang ${ }^{1}$ and Weihua Gong ${ }^{1}$ \\ ${ }^{1}$ Department of Surgery, Second Affiliated Hospital of School of Medicine, Zhejiang University, Hangzhou City, People's \\ Republic of China \\ ${ }^{2}$ Department of Oncology, First Affiliated Hospital of Shihezi University School of Medicine, Shihezi City, People's Republic \\ of China \\ ${ }^{3}$ Division of Gastroenterology, Xiangya Second Hospital, Central South University, Hunan, People's Republic of China \\ * These authors have contributed equally to this work \\ Correspondence to: Weihua Gong, email: weihua.gong@gmail.com
}

Tingbo Liang, email: liangtingbo@zju.edu.cn

Xiaowei Liu, email: liuxw@csu.edu.cn

Keywords: myeloid-derived suppressor cells; Th17 cells; tumor; autoimmunity; cytokine

Received: December 10,2015 Accepted: March 02, $2016 \quad$ Published: March 19, 2016

\section{ABSTRACT}

Myeloid-derived suppressor cells (MDSCs) and Th17 cells were first discovered in the fields of cancer and autoimmunity, respectively. In recent years, their activities have been explored in other biological and pathological conditions, such as infective diseases and solid organ transplantation. However, the interplay between MDSCs and Th17 cells and the mechanism of their interaction remain obscure. This review summarized and analyzed the relationship between MDSCs and Th17 cells, both of which participate in tumor, autoimmune disease, infection and other conditions. In tumors, the increase in MDSCs at the tumor site is usually accompanied by the accumulation of Th17 cells. However, their relationship is inconsistent in different tumors. In arthritic mice or rheumatoid arthritis (RA) patients, an increase in MDSCs, which could ameliorate disease symptoms, causes decreased IL-17A gene expression and Th17 cells accumulation. Furthermore, we concluded that the interaction between MDSCs and Th17 cells is mainly mediated by cytokines. However, the mechanisms require further investigation. Determining the details of their interplay will provide a better understanding of immune networks and could lead to the development of immunotherapeutic strategies in the future.

\section{INTRODUCTION}

Myeloid-derived suppressor cells (MDSCs) were discovered in cancer patients over 20 years ago [1,2]. The suppressive activity of MDSCs on immune responses has been studied widely in recent years [3]. Derived from bone marrow, MDSCs are characterized by a heterogeneous population of immature cells. In mice, MDSCs comprise two subsets, the granulocytic or neutrophilic MDSCs (G-MDSCs, CD11 b ${ }^{+}$Ly $6 \mathrm{G}^{+} \mathrm{Ly} 6 \mathrm{C}^{\text {low }}$ ) and the monocytic MDSCs (MN-MDSCs, CD11b ${ }^{+}$Ly6G-Ly6 ${ }^{\text {high }}$ ) [4-6]. In humans, their phenotypes are Lin-HLA-DR- ${ }^{-} D 33^{+}$and

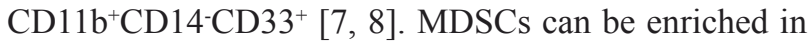

the primary lesion, lymphoid organs and even peripheral blood among various tumor patients. MDSCs function in various conditions, such as autoimmune diseases, pathogen infections, transplant rejection and chronic inflammation [3]. Both innate and adoptive immunity can be suppressed by MDSCs. In addition, they can also exhibit non-immune biological behavior, such as promoting tumor angiogenesis $[9,10]$. The expansion and activation of MDSCs are influenced by their surrounding immune factors, which originate from other activated immune cells or stromal cells [3]. For instance, IL-1 $\beta$ is an inducer of MDSCs expansion, and can be produced by activated MDSCs [11, 12]. MDSCs interplay with other cells through different intracellular pathways, e.g., reactive 
Table1: The crosstalk between MDSCs and Th17 cells in different pathological conditions

\begin{tabular}{|l|l|l|l|l|}
\hline Pathological types & $\begin{array}{l}\text { Number } \\
\text { of articles }\end{array}$ & Disease models & $\begin{array}{l}\text { Publication } \\
\text { year }\end{array}$ & References \\
\hline Tumors & 8 & $\begin{array}{l}\text { Ehrlich acites carcinoma, Colorectal cancer, } \\
\text { Melanoma, Breast cancer, Gastrointestinal cancer, } \\
\text { Esophageal cancer }\end{array}$ & $2011-2014$ & {$[26-33,55]$} \\
\hline Autoimmune diseases & 9 & $\begin{array}{l}\text { Arthritis, Encephalomyelitis, Autoimmune } \\
\text { hepatitis, Systemic lupus erythematosus }\end{array}$ & $2012-2015$ & $\begin{array}{l}{[37,39-45,} \\
56]\end{array}$ \\
\hline Infectious diseases & 2 & $\begin{array}{l}\text { Chagas disease (Trypanosoma cruzi), Cystic } \\
\text { fibrosis lung disease (Pseudomonas aeruginosa) }\end{array}$ & $2013-2014$ & {$[48,49]$} \\
\hline Transplant rejection & 2 & $\begin{array}{l}\text { Graft-versus-host disease (GVHD), Heart } \\
\text { transplantation }\end{array}$ & $2014-2015$ & {$[50,51]$} \\
\hline Immune system development & 1 & None & None & 2013 \\
\hline Only cells in vitro & 2 & [52] & [53, 54] \\
\hline
\end{tabular}

oxygen species (ROS) by G-MDSCs, arginase and NO by M-MDSCs $[6,13]$, and intercellular signaling factors, e.g. TGF- $\beta[14,15]$.

Th17 cells, as the third subset of $\mathrm{T}$ helper cells, are IL-17-producing CD4+ T cells and are abundant at mucosal interfaces [16-18]. Th17 cells have a protective effect against the clearance of extracellular bacterial and fungal infections [19]. They also participate in regulating immune responses in other pathological conditions, such as autoimmune diseases, chronic inflammation, tumors and transplant rejection $[20,21]$. The activation, expansion and differentiation of Th17 cells are controlled by secretory cytokines. The synergistic effect of TGF- $\beta$ plus IL-6 or IL-21 is responsible for Th17 differentiation. IL-23 is essential for Th17 cell survival and stabilization $[18,22]$. Recent studies revealed that IL-23 and IL-1 $\beta$ could induce Th17 cells to produce IL-17 [23]. By contrast, Th17 cells can secrete IL-17A (generally regarded as IL-17), IL17F, IL-21, IL-22, and IL-23, which allow Th17 cells to communicate with other immune or non-immune cells [22]. Given that TGF- $\beta$ alone induces Foxp $3^{+}$T regulatory cells (Tregs) in naive T cells, TGF- $\beta$ plus IL-6 could drive the differentiation of naive T cells to Th17 cells instead, indicating a reciprocal relationship between Th17 cells and Tregs [24]. However, the interplay between MDSCs and $\mathrm{Th} 17 \mathrm{~s}$ remains undefined.

MDSCs are widely recognized to suppress immune responses, while the function of Th17 cells and its secreting factor IL-17 tend to promote inflammation and immune responses. Both MDSCs and Th17 cells have been widely studied in the same pathological conditions, such as tumors and autoimmune diseases. Furthermore, some immune regulatory factors, including IL-1 $\beta$ and TGF- $\beta$, are simultaneously involved in the development, differentiation or activation of MDSCs and Th17 cells. Based on their biological similarities and overlapping fields, this review investigated the possible interplay between MDSCs and Th17 cells in different pathological conditions.

\section{MDSCS ARE ASSOCIATED WITH TH17 CELLS IN VARIOUS PATHOLOGICAL CONDITIONS}

The interplay between MDSCs and Th17 cells is implicated in many pathological conditions such as tumors, autoimmune diseases, infectious diseases and transplant rejection (Table1). It has been primarily studied in the settings of tumors and autoimmune diseases. The details can be summarized and analyzed as follows.

\section{RELATIONSHIP BETWEEN MDSCS AND TH17 CELLS IN TUMORS}

Research on the function of MDSCs is mainly based on tumor studies. It is widely accepted that MDSCs accumulation in the tumor micro-environment can promote tumor development by inhibiting the patient's anti-cancer immune responses [3]. Th17 cells may also be found in tumor lesions. Th17 cells are involved in both tumorigenesis and tumor eradication. However, the precise contribution of Th17 cells to tumors remains obscure [25].

In malignant carcinoma, HLA-G expression is considered as the main escape mechanism to help tumor cells circumvent immune surveillance. In melanoma, a previous study revealed the underlying mechanism of this tumor escape involved the expansion of MDSCs and the absence of Th1/Th17 cytokines [26]. The relationship between MDSCs and Th1/Th17 cells has been further explored. Research into mouse melanoma demonstrated that decreased numbers of Th17 cells could promote tumor growth, which was not associated with the accumulation or suppressive function activation of MDSCs. Instead, it was associated with a decrease of CD4+ T cells in the tumor [27]. In human colorectal cancer, accumulation and expansion of peripheral MN-MDSCs were promoted by an increase of IL-17A, which was mainly secreted by tumorinfiltrating $\gamma \delta \mathrm{T}$ cells rather than Th17 cells [28]. The proportions of MDSCs and Th17 cells in the peripheral 
blood of esophageal cancer patients were both elevated. However, no obvious correlation was found [29].

By contrast, other studies revealed a close relationship between MDSCs and Th17 cells. 5-fluorouracil (5FU) is characterized by its anticancer activity, which is based on the restoration of T-cell immunity via the elimination of MDSCs [30]. Intriguingly, 5-FU can also drive activation of the pyrin domain containing 3 (NLRP3) inflammasome in MDSCs to promote tumor growth and cancer angiogenesis by eliciting Th17 cells and inducing IL-17 production [30]. In detail, NLRP3 dependent caspase- 1 activation leads to IL-1 $\beta$ production, which subsequently induced IL-17 production by CD4+ T cells [30]. In Ehrlich ascites carcinoma, the increased proportion of MDSCs at the tumor site was positively correlated with accumulation of IL-17+T cells. In addition, it was revealed that MDSCs could enhance the Th17 response, which relies on cytokines secreted by MDSCs. Among these cytokines, IL- 6 and TGF- $\beta$ synergistically promoted IL-17 production, whereas IFN- $\gamma$ inhibited IL-17 production [31]. In TGF- $\beta$ receptor II knock-out mice, polyoma middle T (PyMT)-induced tumors were associated with an increased number of Th17 cells, as well as more Th17-inducing cytokines, such as TGF- $\beta$, IL-6, and IL-23. IL-17 upregulates arginase (Arg), indoleamine 2,3-dioxygenase (IDO), and cyclooxygenase-2 (COX-2) to potentiate the suppressive function of MDSCs on anti-cancer immune responses [32]. In addition, some studies focused on the relationship between IL-17 and MDSCs. In gastrointestinal cancer patients, IL-17 production correlated with circulating MDSCs levels [33]. In addition, IL-17 was required for the development and tumor-promoting activity of MDSCs in tumor bearing mice [34].

\section{RELATIONSHIP BETWEEN MDSCS AND TH17 CELLS IN AUTOIMMUNE DISEASES}

Th17 cells were first demonstrated in organ-specific autoimmunity and are closely involved in rheumatoid arthritis (RA), multiple sclerosis and inflammatory bowel disease [22]. IL-17 levels and the number of Th17 cells are positively associated with the progress of RA, whereas MDSCs have the potential to suppress the autoimmune responses and prevent tissue injury [35]. Although the exact function of MDSCs in the expansion of Th17 cells in RA is still unclear, their interplay has been studied extensively in this disease [36]. A series of clinical and experimental studies observed that in arthritic mice or RA patients, MDSCs and Th17 cells were simultaneously expanded and could be detected from the spleen, blood, lymphoid tissues, synovial fluid and inflamed paws [3740]. The proportion of MDSCs was positively correlated with the severity of RA and an inflammatory response of pathogenic Th17 cells. MDSCs show T cell suppressive activity and produce high levels of pro-inflammatory cytokines, including TNF- $\alpha$ and IL-1 $\beta$. In vitro, both human and mouse MDSCs could promote Th17 cell polarization and differentiation in an IL-1 $\beta$-dependent manner [37, 39]. Adoptive transfer of MDSCs to RA mice ameliorated the disease symptoms (delayed onset of arthritis, reduced arthritis scores, and reduced joint inflammation and damage) and caused a concomitant decrease in $I L-17 A$ gene expression and accumulation of Th17 cells in the spleens [39]. Furthermore, transfer of MDSCs could also significantly decrease Th17 cells in draining lymph nodes [40-42]. A clinical study also demonstrated that an increase in the number of circulating MDSCs was negatively correlated with Th17 cells in RA patients [38].

In other autoimmune conditions, it was reported that G-MDSCs were associated with experimental autoimmune encephalomyelitis (EAE) development in mice [43]. G-MDSCs in the EAE model could enhance greatly the differentiation of naive CD4+ T cell precursors into Th17 cells. They increased the numbers of Th17 cells, elevated IL-17A production and enhanced the expression of ROR $\gamma \mathrm{t}$, a key transcription factor that determines Th17 differentiation. During this process, as the major source of IL- $1 \beta$ and TGF- $\beta$, MDSCs promote Th17 differentiation [43]. The transcription factor cyclic adenosine monophosphate-responsive element modulator $\alpha(\mathrm{CREM} \alpha)$ can trigger differentiation of T lymphocytes toward Th17 cells, thus promoting autoimmunity in systemic lupus erythematosus and lung inflammation. However, in the mouse immune-mediated hepatitis model, hepatic MDSCs that overexpressed CREM $\alpha$ did not induce a predominant Th17 response in intrahepatic $\mathrm{T}$ cells [44]. In addition, in a mouse systemic lupus erythematosus (SLE) model, blockade of IL-33 could prevent the progress of SLE, which was associated with expansion of Tregs and MDSCs, and suppression of Th17 cells [45].

\section{RELATIONSHIP BETWEEN MDSCS AND TH17 CELLS IN INFECTIOUS DISEASES}

Th17 cells are involved in host defense against various pathogen infections [21]. However, the functions of MDSCs in infection remain obscure. It was observed that expansion of MDSCs occurs in many types of infections, implying their involvement in anti-infection immune responses [46, 47]. In an acute infection model, represented by infection with Trypanosoma cruzi, the causative agent of Chagas disease, MDSCs were expanded in the liver and spleen. Depletion of MDSCs resulted in a Th17 cells' response associated with very high parasitemia and mortality, although a negative relationship between MDSCs and Th1/Th17 cells was found in the spleen [48]. In a model of pseudomonas aeruginosa-induced cystic fibrosis lung disease, MDSCs were efficiently generated. They dampened $\mathrm{T}$ cell proliferation and the Th17 cell 
response, which subsequently prevented neutrophil recruitment by inhibiting IL-17 release [49].

\section{RELATIONSHIP BETWEEN MDSCS AND TH17 CELLS IN OTHER CONDITIONS}

After bone marrow transplantation, patients with graft-versus-host disease (GvHD) showed an increased proportion of G-MDSCs. In addition, peripheral MNMDSCs efficiently dampened Th1 and Th17 responses [50]. In a cardiac transplant model, our own experimental studies revealed that MDSCs, rather than Th17 cells, are closely involved in transplant tolerance using an IL-6 deficient donor [51]. In cord blood, increased G-MDSCs efficiently suppressed IFN- $\gamma$, IL-5 and IL-17 production, indicating their broad suppressive effects on Th1, Th2 and Th17 lymphocytes [52]. There are also many ex vivo experimental studies that demonstrate an indirect relationship between MDSCs and Th17 cells. Different subsets of myeloid cells isolated from human peripheral blood modulated TGF- $\beta$-dependent CD4+ T cell differentiation in different ways. Human CD14 ${ }^{+} \mathrm{HLA}^{-}$ $\mathrm{DR}^{- \text {/low }}$ MDSCs induced Foxp3 $3^{+}$Tregs, but not Th17 cells, which were instead induced by $\mathrm{CD} 14^{+} \mathrm{HLA}^{-} \mathrm{DR}^{+}$ monocytes. MDSCs catalyzed the transdifferentiation of Foxp $3^{+}$Tregs from monocyte-induced Th17 cells [53]. In ovarian cancer cell lines, induction and stability of human Th17 cells required endogenous NOS2 and cGMPdependent NO, which were produced by human MDSCs [54].

Taken together, the interplay between MDSCs and Th17 cells and the underlying mechanisms of their interaction still need to be explored in depth. Interestingly, the aforementioned studies revealed that intercellular communication between MDSCs and Th17 cells was not dependent on MDSC-Th17 cell contact. Their interaction is partially mediated by secreted cytokines (Figure1).

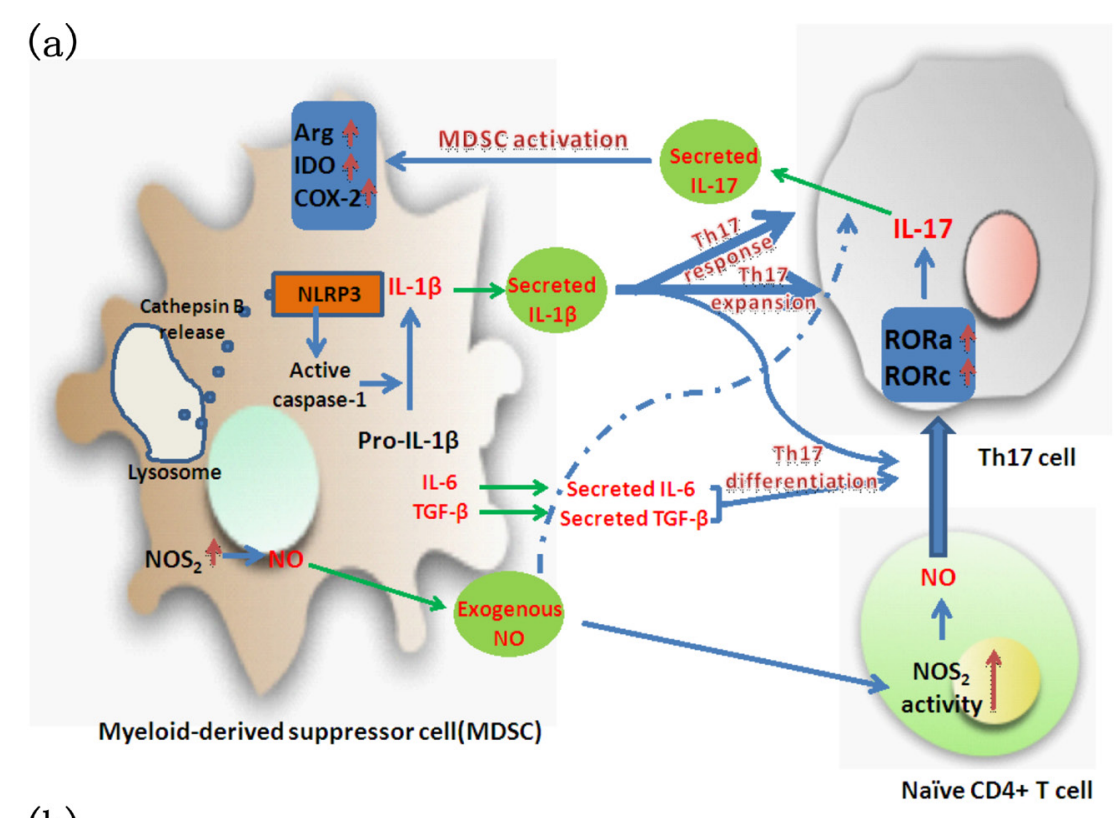

(b)

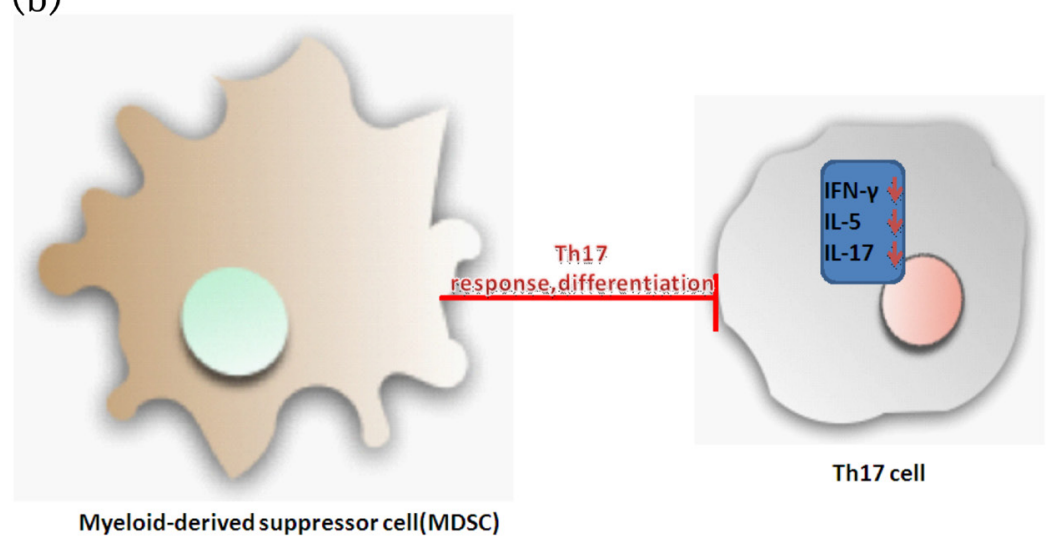

Figure 1: Regulation of the interaction between myeloid-derived suppressor cells (MDSCs) and Th17 cells. a. MDSCs and Th17 cells are mutually promoted; b. MDSCs inhibit Th17 cells activity. Arg, arginase; IDO, indoleamine 2, 3-dioxygenase; COX-2, cyclooxygenase-2; NLRP3, pyrin domain containing-3 protein; ROR, retinoid-related orphan receptor; NOS2, nitric oxide synthase-2; NO, Nitric oxide. 


\section{CONCLUDING REMARKS AND PERSPECTIVE}

In recent years, MDSCs and Th17 cells have been a focus of immunological research. They are involved in the regulation of various immune responses, including both physiological and pathological conditions, especially in the fields of tumor and autoimmunity. Recently, the association of MDSCs with Th17 cells has been studied increasingly. However, the effect of Th17 cells on MDSCs remains unclear, and its determination might increase our understanding of their interplay and other associated biological behaviors. In addition, because of the lack of studies clarifying the functions of MDSCs and Th17 cells in some non-mainstream fields, e.g., infection and transplant rejection, their potential interactions in these fields merit further investigation. To reveal the biological functions of MDSCs and Th17 cells comprehensively, further studies exploring their interactions should focus on mature disease models, such as rheumatoid arthritis. These future studies should clarify the nature of their interplay, which will increase our understanding of the immune networks and aid the development of potential immunotherapeutic strategies.

\section{ACKNOWLEDGMENTS}

The work was supported by the National Science Foundation for Outstanding Young Scholars of China (No. 81522006), the Fundamental Research Funds for the Central Universities, the National Natural Science Foundation of China (No. 81470527, No. 81270323), and Zhejiang Provincial Outstanding Youth Foundation (No. LR13H020001).

\section{CONFLICTS OF INTEREST}

We declare that there is no conflict of interest.

\section{REFERENCES}

1. Buessow SC, Paul RD and Lopez DM. Influence of mammary tumor progression on phenotype and function of spleen and in situ lymphocytes in mice. Journal of the National Cancer Institute. 1984; 73:249-255.

2. Young MR, Newby M and Wepsic HT. Hematopoiesis and suppressor bone marrow cells in mice bearing large metastatic Lewis lung carcinoma tumors. Cancer research. 1987; 47:100-105.

3. Gabrilovich DI and Nagaraj S. Myeloid-derived suppressor cells as regulators of the immune system. Nature reviews Immunology. 2009; 9:162-174.

4. Kusmartsev S, Nefedova Y, Yoder D and Gabrilovich DI. Antigen-specific inhibition of CD8 $+\mathrm{T}$ cell response by immature myeloid cells in cancer is mediated by reactive oxygen species. Journal of immunology. 2004; 172:989999.

5. Hestdal K, Ruscetti FW, Ihle JN, Jacobsen SE, Dubois CM, Kopp WC, Longo DL and Keller JR. Characterization and regulation of RB6-8C5 antigen expression on murine bone marrow cells. Journal of immunology. 1991; 147:22-28.

6. Youn JI, Nagaraj S, Collazo M and Gabrilovich DI. Subsets of myeloid-derived suppressor cells in tumor-bearing mice. Journal of immunology. 2008; 181:5791-5802.

7. Filipazzi P, Valenti R, Huber V, Pilla L, Canese P, Iero M, Castelli C, Mariani L, Parmiani G and Rivoltini L. Identification of a new subset of myeloid suppressor cells in peripheral blood of melanoma patients with modulation by a granulocyte-macrophage colony-stimulation factor-based antitumor vaccine. Journal of clinical oncology. 2007; 25:2546-2553.

8. Poschke I, Mougiakakos D, Hansson J, Masucci GV and Kiessling R. Immature immunosuppressive CD14+HLADR-/low cells in melanoma patients are Stat3hi and overexpress CD80, CD83, and DC-sign. Cancer research. 2010; 70:4335-4345.

9. Sinha P, Clements VK, Bunt SK, Albelda SM and Ostrand-Rosenberg S. Cross-talk between myeloid-derived suppressor cells and macrophages subverts tumor immunity toward a type 2 response. Journal of immunology. 2007; 179:977-983.

10. Murdoch C, Muthana M, Coffelt SB and Lewis CE. The role of myeloid cells in the promotion of tumour angiogenesis. Nature reviews Cancer. 2008; 8:618-631.

11. Rieber N, Singh A, Oz H, Carevic M, Bouzani M, Amich J, Ost M, Ye Z, Ballbach M, Schafer I, Mezger M, Klimosch $\mathrm{SN}$, Weber AN, et al. Pathogenic fungi regulate immunity by inducing neutrophilic myeloid-derived suppressor cells. Cell host \& microbe. 2015; 17:507-514.

12. Bruchard M, Mignot G, Derangere V, Chalmin F, Chevriaux A, Vegran F, Boireau W, Simon B, Ryffel B, Connat JL, Kanellopoulos J, Martin F, Rebe C, Apetoh L and Ghiringhelli F. Chemotherapy-triggered cathepsin B release in myeloid-derived suppressor cells activates the Nlrp3 inflammasome and promotes tumor growth. Nature medicine. 2013; 19:57-64.

13. Movahedi K, Guilliams M, Van den Bossche J, Van den Bergh R, Gysemans C, Beschin A, De Baetselier P and Van Ginderachter JA. Identification of discrete tumor-induced myeloid-derived suppressor cell subpopulations with distinct T cell-suppressive activity. Blood. 2008; 111:42334244.

14. Yang L, Huang J, Ren X, Gorska AE, Chytil A, Aakre M, Carbone DP, Matrisian LM, Richmond A, Lin PC and Moses HL. Abrogation of TGF beta signaling in mammary carcinomas recruits Gr-1+CD11b+ myeloid cells that promote metastasis. Cancer cell. 2008; 13:23-35.

15. Li H, Han Y, Guo Q, Zhang M and Cao X. Cancerexpanded myeloid-derived suppressor cells induce anergy 
of NK cells through membrane-bound TGF-beta 1. Journal of immunology. 2009; 182:240-249.

16. Park H, Li Z, Yang XO, Chang SH, Nurieva R, Wang YH, Wang Y, Hood L, Zhu Z, Tian Q and Dong C. A distinct lineage of CD4 $\mathrm{T}$ cells regulates tissue inflammation by producing interleukin 17. Nature immunology. 2005; 6:1133-1141.

17. Harrington LE, Hatton RD, Mangan PR, Turner H, Murphy TL, Murphy KM and Weaver CT. Interleukin 17-producing CD4+ effector T cells develop via a lineage distinct from the $\mathrm{T}$ helper type 1 and 2 lineages. Nature immunology. 2005; 6:1123-1132.

18. Bettelli E, Korn $\mathrm{T}$ and Kuchroo VK. Th17: the third member of the effector T cell trilogy. Current opinion in immunology. 2007; 19:652-657.

19. Bedoya SK, Lam B, Lau K and Larkin J, 3rd. Th17 cells in immunity and autoimmunity. Clinical \& developmental immunology. 2013; 2013:986789.

20. Miossec P and Kolls JK. Targeting IL-17 and TH17 cells in chronic inflammation. Nature reviews Drug discovery. 2012; 11:763-776.

21. Tesmer LA, Lundy SK, Sarkar S and Fox DA. Th17 cells in human disease. Immunological reviews. 2008; 223:87-113.

22. Korn T, Bettelli E, Oukka M and Kuchroo VK. IL-17 and Th17 Cells. Annual review of immunology. 2009; 27:485517.

23. Mills KH, Dungan LS, Jones SA and Harris J. The role of inflammasome-derived IL-1 in driving IL-17 responses. Journal of leukocyte biology. 2013; 93:489-497.

24. Bettelli E, Carrier Y, Gao W, Korn T, Strom TB, Oukka M, Weiner HL and Kuchroo VK. Reciprocal developmental pathways for the generation of pathogenic effector TH17 and regulatory T cells. Nature. 2006; 441:235-238.

25. Nagaraj S, Youn JI and Gabrilovich DI. Reciprocal relationship between myeloid-derived suppressor cells and T cells. Journal of immunology. 2013; 191:17-23.

26. Agaugue S, Carosella ED and Rouas-Freiss N. Role of HLA-G in tumor escape through expansion of myeloidderived suppressor cells and cytokinic balance in favor of Th2 versus Th1/Th17. Blood. 2011; 117:7021-7031.

27. Nunez S, Saez JJ, Fernandez D, Flores-Santibanez F, Alvarez K, Tejon G, Ruiz P, Maldonado P, Hidalgo Y, Manriquez V, Bono MR, Rosemblatt M and Sauma D. T helper type 17 cells contribute to anti-tumour immunity and promote the recruitment of T helper type 1 cells to the tumour. Immunology. 2013; 139:61-71.

28. Wu P, Wu D, Ni C, Ye J, Chen W, Hu G, Wang Z, Wang C, Zhang Z, Xia W, Chen Z, Wang K, Zhang T, et al. gammadeltaT17 cells promote the accumulation and expansion of myeloid-derived suppressor cells in human colorectal cancer. Immunity. 2014; 40:785-800.

29. Jiao ZJ, Gao JJ, Hua SH, Chen DY, Wang WH, Wang H, Wang $\mathrm{XH}$ and $\mathrm{Xu} \mathrm{HX}$. Correlation between circulating myeloid-derived suppressor cells and Th17 cells in esophageal cancer. World journal of gastroenterology. 2012; 18:5454-5461.

30. Ghiringhelli F, Bruchard M and Apetoh L. Immune effects of 5-fluorouracil: Ambivalence matters. Oncoimmunology. 2013; 2:e23139.

31. Chatterjee S, Das S, Chakraborty P, Manna A, Chatterjee $\mathrm{M}$ and Choudhuri SK. Myeloid derived suppressor cells (MDSCs) can induce the generation of Th17 response from naive CD4+ T cells. Immunobiology. 2013; 218:718-724.

32. Novitskiy SV, Pickup MW, Gorska AE, Owens P, Chytil A, Aakre M, Wu H, Shyr Y and Moses HL. TGF-beta receptor II loss promotes mammary carcinoma progression by Th17 dependent mechanisms. Cancer discovery. 2011; 1:430441.

33. Yazawa T, Shibata M, Gonda K, Machida T, Suzuki S, Kenjo A, Nakamura I, Tsuchiya T, Koyama Y, Sakurai K, Shimura T, Tomita R, Ohto H, Gotoh M and Takenoshita S. Increased IL-17 production correlates with immunosuppression involving myeloid-derived suppressor cells and nutritional impairment in patients with various gastrointestinal cancers. Molecular and clinical oncology. 2013; 1:675-679.

34. He D, Li H, Yusuf N, Elmets CA, Li J, Mountz JD and $\mathrm{Xu} \mathrm{H}$. IL-17 promotes tumor development through the induction of tumor promoting microenvironments at tumor sites and myeloid-derived suppressor cells. Journal of immunology. 2010; 184:2281-2288.

35. Cripps JG and Gorham JD. MDSC in autoimmunity. International immunopharmacology. 2011; 11:789-793.

36. Wang Y, Tian J and Wang S. The potential therapeutic role of myeloid-derived suppressor cells in autoimmune arthritis. Seminars in arthritis and rheumatism. 2016; 45:490-495.

37. Zhang H, Wang S, Huang Y, Wang H, Zhao J, Gaskin F, Yang $\mathrm{N}$ and Fu SM. Myeloid-derived suppressor cells are proinflammatory and regulate collagen-induced arthritis through manipulating Th17 cell differentiation. Clinical immunology. 2015; 157:175-186.

38. Jiao Z, Hua S, Wang W, Wang H, Gao J and Wang X. Increased circulating myeloid-derived suppressor cells correlated negatively with Th17 cells in patients with rheumatoid arthritis. Scandinavian journal of rheumatology. 2013; 42:85-90.

39. Guo C, Hu F, Yi H, Feng Z, Li C, Shi L, Li Y, Liu H, Yu X, Wang H, Li J, Li Z and Wang XY. Myeloidderived suppressor cells have a proinflammatory role in the pathogenesis of autoimmune arthritis. Annals of the rheumatic diseases. 2014.

40. Fujii W, Ashihara E, Hirai H, Nagahara H, Kajitani N, Fujioka K, Murakami K, Seno T, Yamamoto A, Ishino H, Kohno M, Maekawa T and Kawahito Y. Myeloid-derived suppressor cells play crucial roles in the regulation of mouse collagen-induced arthritis. Journal of immunology. 2013; 191:1073-1081.

41. Wang W, Jiao Z, Duan T, Liu M, Zhu B, Zhang Y, Xu 
Q, Wang $\mathrm{R}$, Xiong $\mathrm{Y}, \mathrm{Xu} \mathrm{H}$ and $\mathrm{Lu} \mathrm{L}$. Functional characterization of myeloid-derived suppressor cell subpopulations during the development of experimental arthritis. European journal of immunology. 2015; 45:464473.

42. Zhang L, Zhang $\mathrm{Z}$, Zhang $\mathrm{H}, \mathrm{Wu} \mathrm{M}$ and Wang $\mathrm{Y}$. Myeloid-derived suppressor cells protect mouse models from autoimmune arthritis via controlling inflammatory response. Inflammation. 2014; 37:670-677.

43. Yi H, Guo C, Yu X, Zuo D and Wang XY. Mouse CD11b+Gr-1+ myeloid cells can promote Th17 cell differentiation and experimental autoimmune encephalomyelitis. Journal of immunology. 2012; 189:4295-4304.

44. Hammerich L, Warzecha KT, Stefkova M, Bartneck M, Ohl K, Gassler N, Luedde T, Trautwein C, Tenbrock K and Tacke F. Cyclic adenosine monophosphate-responsive element modulator alpha overexpression impairs function of hepatic myeloid-derived suppressor cells and aggravates immune-mediated hepatitis in mice. Hepatology. 2015; 61:990-1002.

45. Li P, Lin W and Zheng X. IL-33 neutralization suppresses lupus disease in lupus-prone mice. Inflammation. 2014; 37:824-832.

46. Goni O, Alcaide P and Fresno M. Immunosuppression during acute Trypanosoma cruzi infection: involvement of Ly6G $(\mathrm{Gr} 1(+)) C D 11 \mathrm{~b}(+)$ immature myeloid suppressor cells. International immunology. 2002; 14:1125-1134.

47. Van Ginderachter JA, Beschin A, De Baetselier P and Raes G. Myeloid-derived suppressor cells in parasitic infections. European journal of immunology. 2010; 40:2976-2985.

48. Arocena AR, Onofrio LI, Pellegrini AV, Carrera Silva AE, Paroli A, Cano RC, Aoki MP and Gea S. Myeloidderived suppressor cells are key players in the resolution of inflammation during a model of acute infection. European journal of immunology. 2014; 44:184-194.

49. Rieber N, Brand A, Hector A, Graepler-Mainka U, Ost M, Schafer I, Wecker I, Neri D, Wirth A, Mays L, Zundel S, Fuchs J, Handgretinger R, et al. Flagellin induces myeloidderived suppressor cells: implications for Pseudomonas aeruginosa infection in cystic fibrosis lung disease. Journal of immunology. 2013; 190:1276-1284.
50. Rieber N, Wecker I, Neri D, Fuchs K, Schafer I, Brand A, Pfeiffer M, Lang P, Bethge W, Amon O, Handgretinger $\mathrm{R}$ and Hartl D. Extracorporeal photopheresis increases neutrophilic myeloid-derived suppressor cells in patients with GvHD. Bone marrow transplantation. 2014; 49:545552.

51. Gong W, Shou D, Cheng F, Shi J, Ge F and Liu D. Tolerance induced by IL-6 deficient donor heart is significantly involved in myeloid-derived suppressor cells (MDSCs). Transplant Immunology. 2015; 32(2):72-5.

52. Rieber N, Gille C, Kostlin N, Schafer I, Spring B, Ost M, Spieles H, Kugel HA, Pfeiffer M, Heininger V, Alkhaled M, Hector A, Mays L, et al. Neutrophilic myeloid-derived suppressor cells in cord blood modulate innate and adaptive immune responses. Clinical and experimental immunology. 2013; 174:45-52.

53. Hoechst B, Gamrekelashvili J, Manns MP, Greten TF and Korangy F. Plasticity of human Th17 cells and iTregs is orchestrated by different subsets of myeloid cells. Blood. 2011; 117:6532-6541.

54. Obermajer N, Wong JL, Edwards RP, Chen K, Scott M, Khader S, Kolls JK, Odunsi K, Billiar TR and Kalinski $\mathrm{P}$. Induction and stability of human Th17 cells require endogenous NOS2 and cGMP-dependent NO signaling. The Journal of experimental medicine. 2013; 210:14331445.

55. Alizadeh D, Trad M, Hanke NT, Larmonier CB, Janikashvili N, Bonnotte B, Katsanis E and Larmonier N. Doxorubicin eliminates myeloid-derived suppressor cells and enhances the efficacy of adoptive T-cell transfer in breast cancer. Cancer research. 2014; 74:104-118.

56. Ioannou M, Alissafi T, Lazaridis I, Deraos G, Matsoukas J, Gravanis A, Mastorodemos V, Plaitakis A, Sharpe A, Boumpas D and Verginis P. Crucial role of granulocytic myeloid-derived suppressor cells in the regulation of central nervous system autoimmune disease. Journal of immunology. 2012; 188:1136-1146. 